\title{
O INGRESSANTE NA UNIVERSIDADE E O PAPEL DO CENTRO ACADÊMICO EM ATIVIDADES DE ACOLHIMENTO
}

Gabriel Günther da Rosa - gabrielgunther1@hotmail.com

Universidade do Estado de Santa Catarina

R. Paulo Malschitzki, 200 - Zona Industrial Norte

89219-710 - Joinville - SC

Indianara Squersato - indianara.squersato@gmail.com

Universidade do Estado de Santa Catarina

R. Paulo Malschitzki, 200 - Zona Industrial Norte

89219-710 - Joinville - SC

Vitor de Castro Alves - vitorcastroalves@gmail.com

Universidade do Estado de Santa Catarina

R. Paulo Malschitzki, 200 - Zona Industrial Norte

89219-710 - Joinville - SC

Felipe Antônio Ribeiro da Silva - felipe21948@hotmail.com

Universidade do Estado de Santa Catarina

R. Paulo Malschitzki, 200 - Zona Industrial Norte

89219-710 - Joinville - SC

Resumo: Este artigo tem por intuito discutir sobre a realidade dos ingressantes na universidade, entendendo as dificuldades e desafios que estes encontram no ensino superior, principalmente nos primeiros anos da realização do curso, buscando conhecer as possíveis problemáticas e como agir. A partir disso, cientes da necessidade de prover um espaço de acolhimento, realizando atividades amplas e capacitivas, além de fornecer as informações, materiais e meios essenciais, deve ser apresentado sobre o papel da representação estudantil neste cenário, em especial o Centro Acadêmico Democrático de Engenharia Elétrica e como este atua na Universidade do Estado de Santa Catarina para atender os ingressantes, apresentando o perfil destes alunos, bem como as atividades que são desenvolvidas, gerando discussões e perspectivas acerca destes assuntos.

Palavras-chave: Ingressante. Atividades de acolhimento. Centro acadêmico. 


\section{INTRODUÇÃO}

Entendendo as dificuldades e desafios que o estudante encara na universidade, principalmente nos primeiros anos da realização do seu curso, é fundamental que haja um espaço de acolhimento a estes, fornecendo as informações, materiais e meios necessários em um primeiro momento. Entretanto, não somente é preciso fazer atividades amplas e de capacitação, mas também entender as necessidades, buscando saber melhor do público em questão: os próprios ingressantes.

A universidade tem, como suas quatro principais funções, a formação profissional, o alargamento da mente humana, o desenvolvimento do saber humano e a transmissão de uma cultura comum (TEIXEIRA, 1964). Cada vez mais, jovens e adultos, de diferentes raças, classes, realidades e convicções, buscam na universidade a possibilidade de um futuro diferente, com oportunidades que não seriam encontradas caso esta busca não fosse realizada.

$\mathrm{O}$ aumento nesta procura pode ser evidenciado pelo aumento na quantidade de instituições de ensino e no número de cursos ofertados, os meios de subsídio para viabilizar a sua realização - como a oferta de bolsas acadêmicas, programas federais, dentre outros - e uma ampliação no poder aquisitivo da população. Junto a isso, a pressão pela obtenção de formação acadêmica e superior, a dificuldade em encontrar empregos qualificados e a abertura da Universidade a novos públicos, como estudantes de idades avançadas, grupos minoritários e vulneráveis, ou de pessoas com deficiência incrementam estes números (ALMEIDA e SOARES, 2003).

$\mathrm{O}$ aluno que está ingressando na universidade pode estar submetido a uma série de dificuldades em um primeiro momento. A decepção com as disciplinas e professores que irá se deparar, problemas com o gerenciamento do tempo e a carga horária do curso, dificuldades em provas e trabalhos, desmotivação e sobrecarga são alguns dos empecilhos listados por Dias, Carlotto, Oliveira e Teixeira (2019). Em outros casos, a necessidade de estar longe da família, o nível do aprendizado e dificuldades intrapessoais também podem interferir na experiência que o calouro irá vivenciar neste período.

Por conta deste universo de variáveis e empecilhos que podem impactar na vida do ingressante na universidade, Cunha e Carrilho (2005) entendem por ser necessária uma atenção especial com o ingressante universitário, com atividades capazes de facilitar a adaptação, haja vista pesquisas que revelam dificuldades pessoais e acadêmicas nestes alunos.

Segundo Teixeira et al. (2008), é necessário prover aos ingressantes informações relativas à vida acadêmica, prestar apoio efetivo na realização de atividades essenciais, bem como propor atividades de integração entre os cursos e serviços especializados a fim de amenizar as dificuldades encontradas, principalmente, no primeiro ano de curso.

\section{O ACOLHIMENTO DE INGRESSANTES NA UNIVERSIDADE}

Ciente da problemática apresentada no Centro de Ciências Tecnológicas (CCT), da Universidade do Estado de Santa Catarina (Udesc), a Direção Geral, por meio da Direção de Extensão, promove junto aos Centros Acadêmicos (CAs), Diretório Acadêmico Nove de Março (DANMA) e Associação Atlética Acadêmica CCT (AAACCT) deste centro eventos de recepção aos calouros. Entretanto, para seguir com as atividades desenvolvidas e uma breve discussão sobre elas, faz-se necessário entender o papel dos centros acadêmicos, em especial o Centro Acadêmico Democrático de Engenharia Elétrica (CADEE), analisando também o perfil dos ingressantes no curso de Engenharia Elétrica. 


\subsection{Os centros acadêmicos e o CADEE}

O movimento estudantil, propriamente dito, teve seu início no Brasil na década de 1930, com a criação da União Nacional dos Estudantes (UNE), sofrendo mudanças e encarando problemas nos anos seguintes (FERRARI, 2013). Hoje, todos os cursos de nível superior têm assegurado o direito à representação que é estabelecida por um centro acadêmico ou diretório acadêmico, de acordo com a Lei n ${ }^{\circ} 7.395$ (BRASIL, 1985).

As entidades estudantis têm as inúmeras funções em assimilar as mais variadas áreas da graduação, dentre elas o desenvolvimento do ensino, onde pode-se destacar a recepção dos calouros, a organização das viagens técnicas e minicursos, contribuindo com a integração e a formação completa do estudante.

O curso de bacharelado em Engenharia Elétrica da Universidade do Estado de Santa Catarina é representado há 30 anos pelo CADEE. Seus alunos, atualmente cerca de 375, também são representados pelo DANMA, que atende aos 8 demais cursos do CCT, e pelo Diretório Central de Estudantes Antonieta de Barros (DCE). Estas entidades estudantis têm, na Universidade, seu funcionamento amparado pela Pró-Reitoria de Extensão, Cultura e Comunidade (Proex), por meio da Coordenadoria de Assuntos Estudantis (CAE).

O CADEE possui seu estatuto junto ao DANMA, responsável por organizar as eleições para o centro acadêmico. Nestas eleições, todos os alunos regularmente matriculados no curso de Engenharia Elétrica podem votar nas chapas candidatas ao mandato de um ano. O centro acadêmico é responsável pela organização de eventos de cultura, esporte e integração, visitas técnicas, debates, discussões, palestras, venda de produtos e mediação na solução de problemas encontrados entre alunos e departamento.

Também está presente em outras formas de representatividade estudantil, incentivando membros a se candidatar e participar do Colegiado Pleno do Departamento de Engenharia Elétrica (CPDEE), onde podem colaborar de forma mais direta no desenvolvimento do próprio curso e intervindo nas pautas de interesse dos alunos.

Como sendo a entidade responsável por atender e representar os alunos do seu curso, o CADEE mantém uma preocupação especial com os ingressantes, visto que, agindo de maneira satisfatória e ampla nos primeiros momentos na universidade, é capaz de diminuir a chance de os calouros encontrarem dificuldades ao longo dos anos. Por isto, buscou analisar o perfil do ingressante nos últimos anos, mapeando suas características e planejando suas atividades de acolhimento.

\subsection{Perfil dos ingressantes no curso de Engenharia Elétrica da Udesc}

$\mathrm{O}$ ingresso no bacharelado em Engenharia Elétrica da Udesc é feito por meio de vestibulares semestrais, um de inverno e um de verão, e pelo Sistema de Seleção Unificada (SISU), onde são disponibilizadas 40 vagas, sendo $75 \%$ preenchidas pelo vestibular e $25 \%$ pelo SISU. Ainda, é adotado o sistema de cotas, sendo $20 \%$ das vagas para estudantes de escolas públicas e $10 \%$ para o grupo racial negro.

Uma pesquisa realizada pelo CADEE junto aos ingressantes no curso de Engenharia Elétrica desde o primeiro semestre de 2018 até o primeiro semestre de 2020 apontou que, com relação aos que responderam, $68,6 \%$ dos alunos eram oriundos de escolas privadas. Além disso, um terço destes alunos haviam realizado algum curso técnico anteriormente.

\subsection{Atividades de acolhimento desenvolvidas}

As entidades estudantis do CCT assumem fortemente o compromisso do acolhimento junto aos ingressantes, estando presentes já no dia de matrícula desses, onde geralmente se encontram com um responsável junto. Neste primeiro momento, é possível repassar algumas informações básicas sobre o curso, o centro, programas de auxílio e, se necessário, 
informações sobre a cidade. Também é realizada a venda de produtos personalizados, incentivando o aluno a se motivar com sua vinda ao novo curso.

Para sua primeira semana de aulas são desenvolvidas diversas atividades de acolhimento. A primeira delas são as Calouríadas, integração solidária amparado pela própria Direção Geral e organizada pela AAACCT junto aos CAs. Neste evento, que ocorre no decorrer da semana, são feitas provas de gincanas, esportes e arrecadações entre os cursos, fornecendo um espaço onde seja possível ter contato entre todos os ingressantes e diversos veteranos que participam para apoiar e motivar o seu time.

Também é organizada uma série de apresentações aos ingressantes. Logo no primeiro dia de aula, o CADEE recepciona a turma de calouros para uma aula trote, onde é apresentado o Centro Acadêmico e sua estrutura, além de como irá funcionar a primeira semana de aulas. Em seguida, os alunos também se apresentam e, então, são levados para um primeiro tour pela Udesc, onde são apresentados às suas principais estruturas, como ginásio, biblioteca, departamento do curso, direção, reprografia e restaurante universitário. Por fim, no próprio restaurante, encontram-se os demais cursos e ocorre uma breve apresentação da Direção Geral, seguido por apresentações culturais, como a da Bateria Universitária, o BatuCÃO, das Cheerleaders CCT, do Coral Universitário e o Show da Física.

Ainda no decorrer da primeira semana, o CADEE realiza um segundo tour com os calouros, onde eles são levados a conhecer alguns dos projetos de ensino e extensão da Universidade, principalmente os do curso de Engenharia Elétrica, onde teriam maior probabilidade de ingressar no futuro. Um terceiro tour ainda acontece, onde o CA, em parceria com o projeto de ensino I Heart Engenharia, do PET Engenharia Elétrica da Udesc, leva os calouros aos laboratórios do curso. Neste momento, lhes são apresentadas as áreas de pesquisa presentes na Engenharia Elétrica e os seus respectivos laboratórios, onde o professor responsável apresenta algumas das pesquisas desenvolvidas e o que eles devem estar aprendendo ao visitar este laboratório no decorrer da graduação.

Voltando a primeira semana de atividades, ainda são realizadas apresentações sobre o funcionamento do Sistema de Gestão Acadêmica (SIGA), ferramenta utilizada para registro de notas, materiais, requisições e realização da rematrícula, dentre outras funcionalidades. São feitas, também, palestras com egressos e bate-papos sobre todos os assuntos discutidos, visando sanar todas as dúvidas possíveis.

Apesar da grande preocupação com a turma logo no seu ingresso, o CADEE segue acompanhando e monitorando seu desempenho no decorrer do semestre, sempre disponível para auxiliar caso problemas venham a ocorrer.

Além dessas atividades, vale destacar a atuação do Serviço de Orientação ao Estudante (SOE), prestado pela Diretoria de Extensão e que trabalha com orientação e auxílio psicológico, atendendo os estudantes que venham a necessitar deste tipo de serviço no decorrer do seu curso.

\section{CONSIDERAÇÕES FINAIS}

As atividades desenvolvidas são variadas e atingem diferentes pontos onde o trabalho com os calouros merece atenção, como a apresentação das funcionalidades essenciais da universidade, desenvolvimento de atividades de integração, palestras e informativos sobre gestão de tempo e otimização da carga horária, além de possibilitar um atendimento sério e de qualidade caso o assunto seja problemas psicológicos.

No que se trata à efetividade das atividades, pode-se notar o interesse, pelos estudantes, de participarem de projetos de ensino e extensão, ou até mesmo de seus centros acadêmicos ou Atlética desde cedo no curso, que permitem a eles se desenvolver de maneira incomparável 
aos que somente permanecem com sua rotina de estudos. Em levantamento realizado na mesma pesquisa apresentada anteriormente, foi questionado se os alunos já haviam participado, ou participavam, de projetos na universidade. Descartando os ingressantes do semestre de 2020, visto o pouco tempo que haviam ingressado, aproximadamente $39 \%$ afirmaram participar ou já ter participado dos projetos.

Entretanto, ao descartar, também, os estudantes que não participaram das atividades de acolhimento, os números subiram para $50 \%$, o que pode começar a indicar certa efetividade nas atividades até então desenvolvidas.

Os dados apresentados sugerem a tendência de que estas atividades possam estar cumprindo o seu papel, mas apenas analisa estes resultados não é o suficiente, visto que em pesquisas mais aprofundadas, apresentado os dados referentes ao abandono e evasão do curso, bem como contar com todas as respostas dos atingidos, poderiam contribuir para um melhor entendimento sobre quão importantes e impactantes estas atividades são e atendem seu objetivo.

Apesar disso, o CADEE busca discutir suas atividades em reuniões de planejamento contendo como novos membros alguns dos últimos ingressantes, recebendo os feedbacks das atividades e buscando melhorá-las. Também mantém contato direto com os projetos de ensino e extensão da Universidade, facilitando a organização de eventos para atingir as turmas de ingressantes, além de ser ativo e trazer melhorias para as atividades desenvolvidas pela Direção na semana de acolhimento o que, mesmo que majoritariamente voltada para calouros, também trazem benefícios diretos e indiretos para veteranos.

Para os próximos anos, o compromisso deve ser mantido e a responsabilidade em promover aos calouros um ambiente cada vez melhor no seu ingresso deve ser intensificada, visando amenizar as dificuldades encontradas e provendo todas as informações e assistências necessárias para que o aluno possa seguir plenamente capaz de desenvolver suas atividades e buscar o seu diploma.

\section{Agradecimentos}

Somos gratos à Universidade do Estado de Santa Catarina que, por meio da Coordenadoria de Assuntos Estudantis, presta o devido apoio e valor às ações e atividades realizadas pelas entidades estudantis da instituição, além de proporcionar aos estudantes uma educação pública, gratuita e de qualidade. Também agradecemos a Direção Geral do Centro de Ciências Tecnológicas da Udesc, junto às Direções de Ensino, Pesquisa e de Extensão, pela preocupação com seus alunos e o compromisso pela transformação do ensino. E, por fim, um agradecimento ao Departamento de Engenharia Elétrica da Udesc, sempre apoiando nas atividades a serem realizadas, além do engajamento em tornar este curso cada vez mais imponente.

\section{REFERÊNCIAS}

ALMEIDA, L. S.; SOARES, A. P. Os Estudantes Universitários: Sucesso Escolar e Desenvolvimento Psicossocial. In: MERCURI, E.; POLYDORO, S. A. J. Estudante Universitário: Características e Experiências de Formação. Taubaté: Cabral Editora e Livraria Universitária, p. 15-40, 2003.

BRASIL. Lei $n^{\circ} 7.395$, de 31 de outubro de 1985. Dispõe sobre os órgãos de representação dos estudantes de nível superior e dá outras providências. Disponível em:

$<$ http://www.planalto.gov.br/ccivil_03/leis/L7395.htm>. Acesso em 01 jun. 2020. 
"Os desafios para formar hoje o engenheiro do amanhã"

CUNHA, Simone M.; CARRILHO, Denise M. O processo de adaptação ao ensino superior e o rendimento acadêmico. Psicologia Escolar Educacional, Campinas, v.9, n.2, p. 215-224, dez. 2005. Disponível em:

$<$ https://www.scielo.br/scielo.php?pid=S1413-85572005000200004\&script=sci_arttext $>$. Acesso em 01 jun. 2020.

DIAS, A. C. G.; CARLOTTO, R. C.; OLIVEIRA, C. T.; TEIXEIRA, M. A. P. Dificuldades percebidas na transição para a universidade. Revista Brasileira de Orientação Profissional, Florianópolis, v.20, n.1, p. 19-30, jan.-jun. 2019. Disponível em:

$<$ http://pepsic.bvsalud.org/pdf/rbop/v20n1/03.pdf>. Acesso em 01 jun. 2020.

FERRARI, Taiza Lira. Revendo a história do movimento estudantil brasileiro. In: PARANÁ. Secretaria de Estado da Educação. Os desafios da Escola Pública Paranaense na Perspectiva do Professor PDE: Produção Didático-pedagógica, 2013. Curitiba: SEED/PR., 2016, v.2. (Cadernos PDE). Disponível em:

$<$ http://www.diaadiaeducacao.pr.gov.br/portals/cadernospde/pdebusca/producoes_pde/2013/2 013_unioeste_ped_pdp_taiza_lira_ferrari.pdf $>$. Acesso em 01 jun. 2020.

TEIXEIRA, Anísio. Funções da universidade. Boletim Informativo CAPES. Rio de Janeiro, n.135, p.1-2, fev. 1964. Disponível em:

$<$ http://www.bvanisioteixeira.ufba.br/artigos/funcoes.html>. Acesso em 01 jun. 2020.

TEIXEIRA, M. A. P., DIAS, A. C. G., WOTTRICH, S.H., OLIVEIRA, A.M. Adaptação à universidade em jovens calouros. Psicologia Escolar Educacional, Campinas, v.12, n. 1, p. 185-202, jun. 2008. Disponível em:

$<$ https://www.scielo.br/scielo.php?pid=S1413-85572008000100013\&script=sci_arttext $>$.

Acesso em 01 jun. 2020.

\title{
THE INGRESSING AT THE UNIVERSITY AND THE ROLE OF THE ACADEMIC CENTER IN RECEPTION ACTIVITIES
}

\begin{abstract}
This article aims to discuss about the reality of ingressing at the university, understanding the difficulties and challenges they encounter in high education, especially in the first of the course, seeking to know the possible problem and how to act. From that, aware of the necessity to provide a recepting space, carrying out broad and capacitive activities, in addition to providing informations, materials and essentials means, it should be presented about the role of the student representation in this scenario, especially the Democratic Academic Center of Electrical Engineering and how it works at State University of Santa Catarina to meet the newcomers, presenting their profile, the activities developed, generating discussions and perspectives on the subject.
\end{abstract}

Keywords: Newcomers. Reception activities. Academic center. 